\title{
Memorial and Museum for the African Burial Ground, New York, New York
}

\author{
FELECIA DAVIS \\ New York Institute of Technology \\ USA
}

\section{UNCOVERING}

a stroll along Manhattan Streets reveals almost nothing except dark faces to connect the Negroes with the history of New York City.

$$
\begin{array}{r}
- \text { M.A. Harris } \\
\text { A Negro History Tour of Manhattan, } 1968
\end{array}
$$

In 1991 excavation for a 34 story Federal office tower at Broadway between Duane and Reade streets in lower Manhattan unearthed for the public a site titled on colonial maps as the "Negro Burial Ground." This place which occupied the margins of the Dutch colonial city, later the edge of the encroaching palisade construction, was the final resting place for free Africans, slaves and other impoverished people. In the seventeenth century the grounds were the only space where Africans free and slave could meet together so that the burial ground was also a political rallying space. This burial ground was the Africans only autonomous space, the only space where they were allowed to congregate with regularity in large numbers.

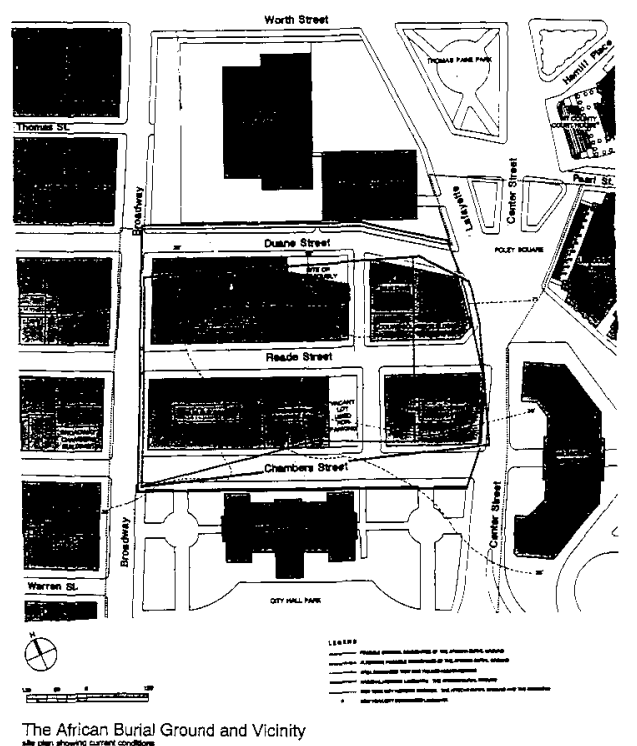

Figure 1. Map of the African Burial Ground
In the early nineteenth century the grid of the expanding city had completely erased the burial grounds, which remained under parking lots until 1991. In 1991 and 1992, archaeological teams documented their findings. This dig presented other representations of life in Manhattan, other surfaces to be read. Four hundred twenty bodies were excavated and are currently undergoing examination to frame the grounds within a bio-cultural context which draws upon historical and archaeological data to reconstruct conditions for this group of people. One of the most painful struggles was over what was documented about the space and people, and what questions should be included as part of a research outline. Other people felt that the display of the skeletons and research on the space profaned dead ancestors and sacred space.

After many battles the site was declared in the late winter of 1992 a National and Civic landmark and renamed, The African Burial Ground. The Federal office tower is nearing completion and a plot of land on the North face of the building has been set apart as a memorial space. The site is of great spiritual and inspirational significance, and provides a rare physical document of what were transient, ephemeral spaces African Americans inhabited in the urban landscape. This proposal for a Memorial and Museum for the African Burial Grounds, reclaims the entire site, including the block which was disturbed by excavation for the tower and makes a physical place, to connect the dark faces to the history of the city.

\section{RECOVERING}

The American Negro is a unique creation: he has no counterpart anywhere, and no predecessors.

The Muslims react to this fact by referring to the Negro as the "So called American Negro" and substituting for the names inherited from slavery the letter $\mathrm{X}$.

- James Baldwin 1968 
There is something compelling about this $\mathrm{X}$. It erases and creates identity simultaneously. $X$ is ubiquitous and its meaning thus ambiguous. $\mathrm{X}$ resists ownership resulting in constant appropriation, It makes the invisible visible or the visible invisible. Is there an " $\mathrm{X}$ " in the architectural discipline which may begin to speak of the situation of the so named "African American" Architect? I am interested in architectural representations that operate like the $\mathrm{X}$ in the name Malcom X.

My inheritance as an architect, an "African American" Architect, is rooted with the image. A most ephemeral and superficial root. I am removed from African traditions and heritage in time and space but am re-connected by fragmented images and information. These obliterating representations also clarify. On the surface of these images is a space for an architectural representation that operates like the mark " $X$ ".

These issues were lodged architecturally by recovering this sacred place in the city with a continuous skin. By lodging this architecture in this skin, shroud or cloth, it provided space to look at problems of African American identity in architectural terms. What was a superficial condition became the primary structuring element. Each part of the program, Memorial and Museum, was looked at in relationship to its covering or uncovering by this surface. There were many identities in this surface.

The Memorial took the form of a sandblasted glass covering, akin to a burial shroud, which at the beginning of the use of the burial grounds in colonial Manhattan were forbidden for fear they concealed weapons for revolt. This shroud was a layer laid on top of the grid of the city streets and covered the entire grounds not just the site of excavation. The grounds, as such, would wipe out the grid and be seen in the city through the grid. The Federal tower was eliminated, the land was viewed as sacred, its value underscored by the absence of repetitious floor plates. The Memorial was thought of as one surface because it allowed space making independently of traditional, gridded building systems. This surface also did away with the notion of establishing a datum or origin and undermined the idea of working in figure and ground or mutually defining black and white. At the block of the excavation, called block 154, this layer of sandblasted glass was disturbed and folded to make a canopy for the hole the archaeologists left. This was not the type of dig where there were substantial ruins exposed, there was primarily churned soil, and after the bodies had been taken and stored for research there could be no more origin. So, at block 154 the shroud was folded to make a new space below it. It was proposed that ancestors be ceremoniously re-intered into the skin, the same surface which would provide a protecting canopy of concealment for this ceremony.

In my research, my own search for origin, I came across several articles about the use and display of cloth during West African funerals. The cloth was an important element in these funerals in that it covered the bodies of the dead and the living, it was also used to decorate the laying out space.

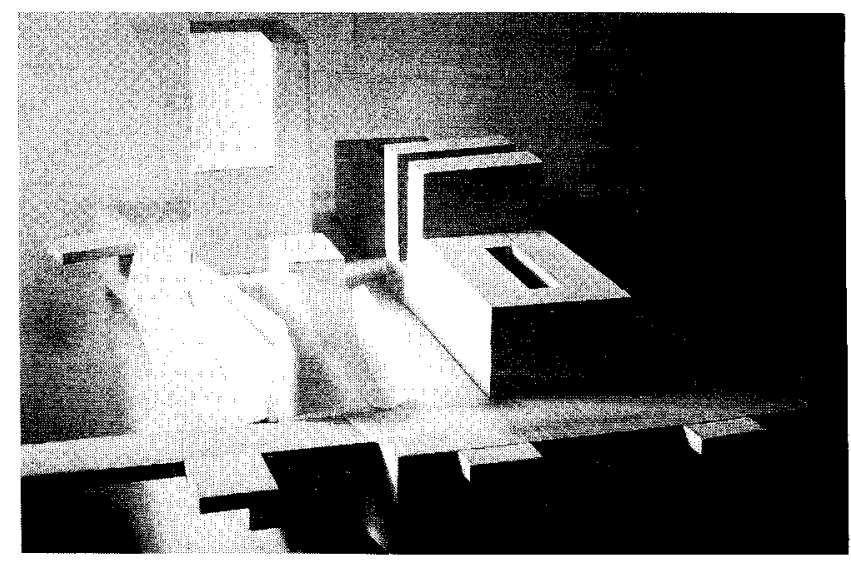

Figure 2. Model of Entire Burial Ground Site with Folded Memorial Space and Museum Wedge

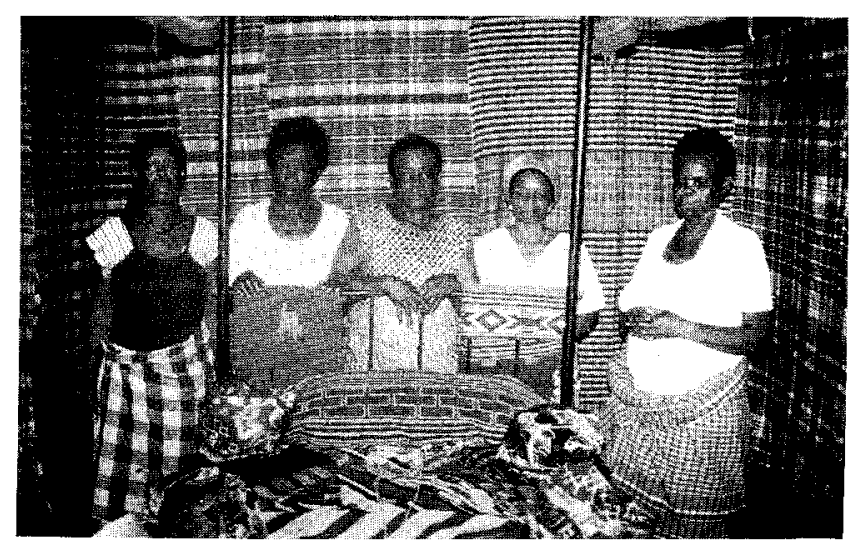

Figure 3. A Laying Out Room, A Kalabari Funeral

These rooms were quite a production and were organized by the women of the family. The more important the deceased, the greater number of laying out rooms and quantity and quality of cloth, the more elaborate the folded displays and more elaborate garments worn by the family. These cloth displays were elaborately folded and placed on beds and tables in the rooms. The fold lines of my cloth came from two important site lines. One was the diagonal at the North boundary of the burial grounds at block 154 the other was an old block line from the city grid. Together these lines marked my fold.

The pattern for the glass came from the archaeologists drawings of the excavated bodies. Each body was marked with a line which made another system off the archaeologists gird, or the city grid. This drawing became a base pattern for the shroud curtain wall. The body lines became the structure to which the glass was fastened, these in turn were supported by vertical members which marked the 20 foot archaeologists grid. Scratches were made in the glass generated from the body line drawing. Finally a pattern taken from a pattern book of African designs was transformed and etched onto the glass. This pattern started off as a carving on the surface of a small wooded West African sculpture. It is a superficial decoration, yet, like the $\mathrm{X}$ in Malcom X, it carries the burden of African American identity for this project. I, given my 


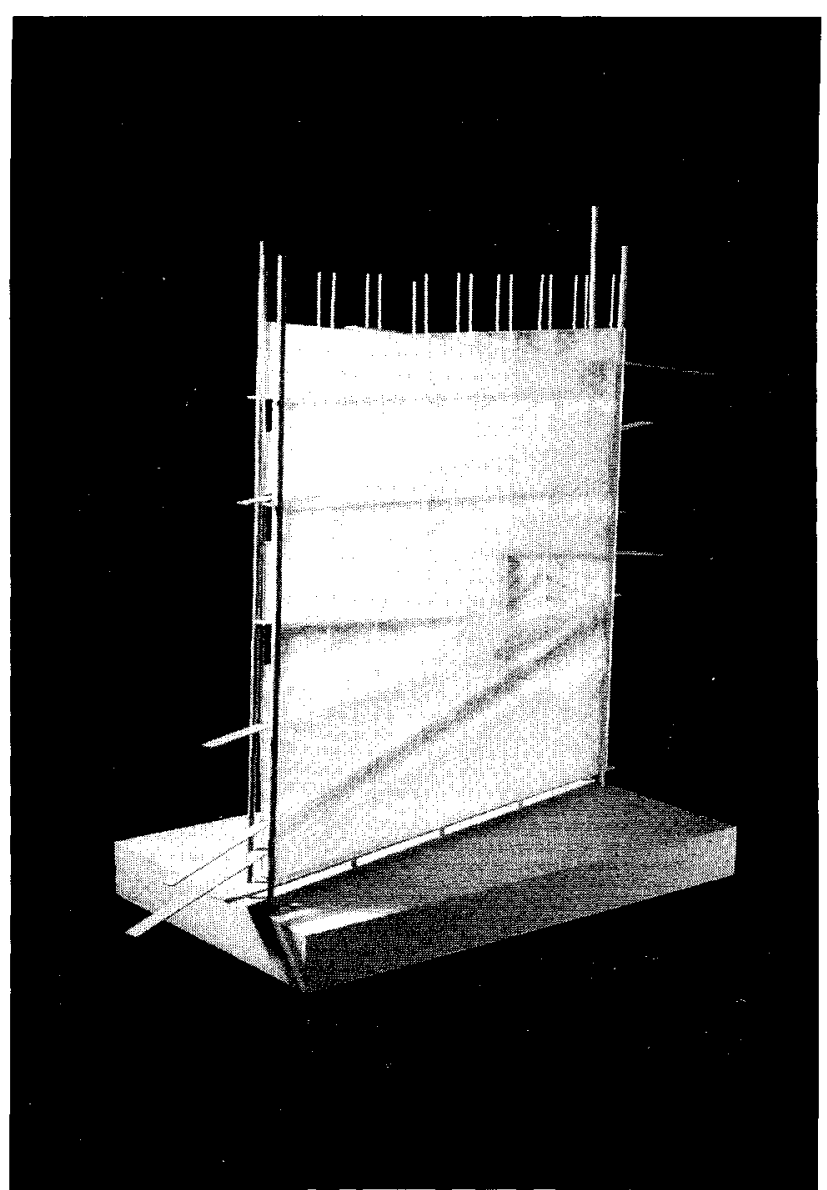

Figure 4. Curtain Wall/Shroud

cultural background, which is American, would never fully comprehend the richness and power of what I had researched. In the case of the pattern, I did not know if what I appropriated had a particular meaning or perhaps no meaning in its culture of origin. What was clear was that African art, traditions and culture would always be seen through the impenetrable veil of my culture, American culture.

This problem was at the heart of this architectural project and explored through the Museum. The Museum occupied a wedge between the diagonal north limit of the Burial Ground, and the North line of block 154. The Museum wedge is concrete and served as a device to frame the surface of the burial shroud. The interface between the Museum and the Memorial was of primary interest. This large scale section shows that interface. On the Museum side pieces of the curtain wall veil were removed to a second layer and objects which were found during the archaeological dig were uncovered in it allowing scrutiny. However, this viewing was frustrated as objects and images were cut and fractured by the configuration of the skin. Another layer back was the reinternment strata. This layer ran throughout the project but bodies were only buried in the reinternment space in opaque

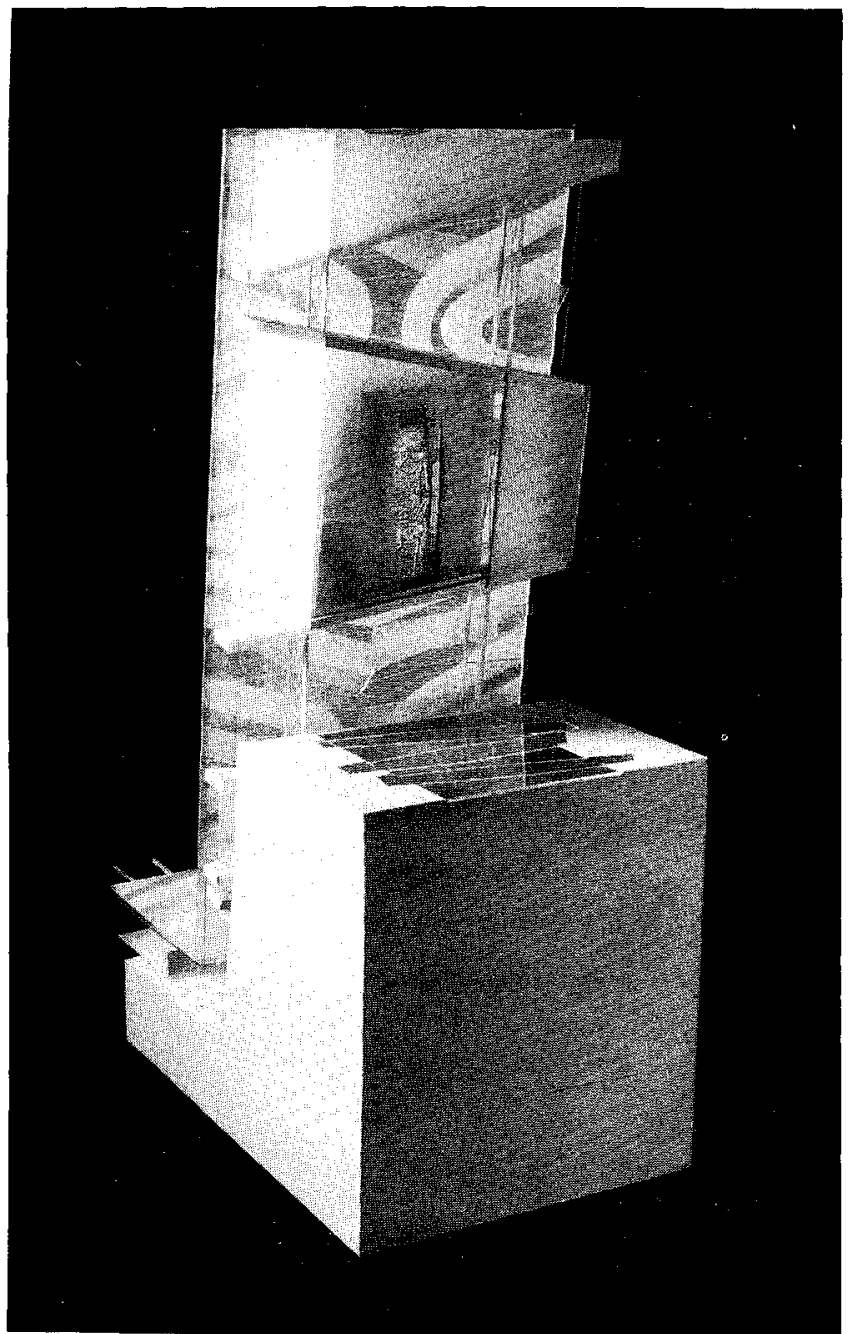

Figure 5. Detail Section of Museum/Memorial Curtain Wall Interface

glass, having been wrapped in fabric of the same African pattern. The last layer revealed scratches underneath the skin of the African pattern which faced the interior of the reinternment space.

I had hoped to make an architecture seen and read as African, but seen and developed through the systems by which "African" was known to me. I am not interested in the nostalgic inscription of an African Architecture, but in critical invention which reconfigures African and its traditions and allows for many identities to coexist simultaneously.

\section{NOTES}

Figure 4 from "Kalabari Funerals: Celebration and Display" by Joanne B. Eicher \& Tonye V. Erekosima, African Arts Vol. 21 1988 pp. $38-45$. 